\title{
Measurement of water-holding properties of fibre and their faecal bulking ability in man
}

\author{
BY M. A. EASTWOOD, J. A. ROBERTSON*, W. G. BRYDON \\ AND DOROTHY MACDONALD \\ Wolfson Gastrointestinal Laboratories, Department of Medicine, Western General \\ Hospital, Crewe Road South, Edinburgh EH4 $2 \mathrm{XU}$
}

(Received 15 November 1982 - Accepted 8 July 1983)

\begin{abstract}
1. Experiments to measure the effect of a fibre source in the diet on stool bulk are difficult and lack precision. In vitro methods which would identify fibre sources that are effective for clinical and epidemiologic use would be valuable. One important property of fibre which influences the ability of fibre to increase stool weight is its water-holding capacity (WHC).

2. WHC was measured using centrifugation, filtration, suction pressure and water flow-rate techniques using fibre concentrates of potato, cereal bran and gum arabic.

3. Dietary supplementation of three preparations of potato fibre $(20 \mathrm{~g} / \mathrm{d})$ had no significant effect on stool weight but $16 \mathrm{~g}$ bran/d increased stool weight from 107 (SE 44) $\mathrm{g} / \mathrm{d}$ to 174 (SE 51) $\mathrm{g} / \mathrm{d}$.

4. The effects of these fibres on stool weight can be related to the nature of the water-holding properties of fibre rather than absolute WHC.
\end{abstract}

The fibre content of the diet has been considered to be a significant factor which influences stool weight (Eastwood et al. 1980). A number of trials have examined the effect which various fibre sources have on intestinal behaviour, stool weight and constituents (Kelsay, 1978; Stephen \& Cummings, 1979). These have shown that cereal bran is more effective in increasing stool weight than either fruit- and vegetable-fibre sources or gel-forming polysaccharides.

Each trial is time-consuming and the usefulness of the information obtained is limited and, hence, complicates comparison of information from separate trials. An in vitro test which would enable a prediction to be made of the stool-bulking ability of any fibre source would reduce the need for many time-consuming trials. Because of the complex chemistry and physical nature of the fibre, however, and the susceptibility of fibre to be modified by bacterial activity in the colon (Stephen \& Cummings, 1980a), no single test may meet this need. Fermentation products from the polysaccharides, e.g. volatile fatty acids and increased bacterial mass (Hellendoorn, 1978), may affect stool weight. This paper describes a study of the water-holding properties of fibre and how these relate to stool-bulking ability.

\section{EXPERIMENTAL \\ Materials}

Potato fibre was a concentrate of potato fibre provided by Nordreco Nestlé Ltd, Bjuv, Sweden. The potato fibre had been dried either by a stream of hot air at $60^{\circ}$ or between hot rollers. Boiled potato fibre was a preparation of the original potato fibre boiled for $25 \mathrm{~min}$ in $500 \mathrm{ml}$ distilled water.

The bran used was a Canadian Red Spring Wheat bran of coarse particle size obtained from Chancelot Mills, Edinburgh. 


\section{Methods and subjects}

Chemical analyses. The fibre preparations used as dietary supplements were analysed by Nordreco Nestlé Ltd.

Fibre analyses were on dried preparations using standard methods (Schweitzer \& Würsch, 1981). Protein was estimated as nitrogen (Kjeldahl; $\mathrm{N} \times 6.25$ ) and starch colorimetrically as glucose after amylase (EC 3.2.1.1 and 3.2.1 .2) treatment. The particle size distribution of the preparations was investigated by passage through sieves and the residue held by each sieving weighed.

Water-holding capacity $(W H C)$. This was determined using centrifugation (McConnell et al. 1974) and filtration techniques (Robertson \& Eastwood, 1981 a). Fibre samples were soaked at room temperature in distilled water at rest for $72 \mathrm{~h}$ before WHC determination. In the centrifugation method, weighed samples of the soaked fibre, equivalent to $0.3-0.5 \mathrm{~g}$ dry fibre, were transferred to $25 \mathrm{ml}$ tared polypropylene centrifuge-tubes containing $20 \mathrm{ml}$ distilled water. Tubes were shaken to suspend the fibre in the water then left to stand for $1 \mathrm{~h}$ before centrifugation at $6000 \mathrm{~g}$ for $15 \mathrm{~min}$. The supernatant fraction was discarded and the tubes left to drain for $30 \mathrm{~min}$ at room temperature. The weight of the wet material in each tube was determined before freeze-drying to determine the WHC. In the filtration method the samples of soaked fibre were filtered through Whatman no. 1 filter paper previously-saturated with distilled water. After filtration was complete $(10 \mathrm{~min})$ a sample of the residues was weighed and freeze-dried to determine the WHC.

Standard errors (variation between duplicate determinations) were used to estimate significant differences between results. The mean (with SE) values for different WHC values $(\mathrm{g} / \mathrm{g})$ were: $5(0 \cdot 6), 6-10(1 \cdot 0), 11-15(1 \cdot 3), 16-20(1 \cdot 5), 20-30(2 \cdot 0)$.

The WHC of each fibre preparation was determined against the suction pressure (i.e. difference in osmotic potential between the fibre and external medium) generated by polyethylene glycol (PEG; molecular weight 6000) (Robertson \& Eastwood, 1981b). Samples of pre-soaked fibre were transferred to dialysis bags $(19 \mathrm{~mm}$ diameter Visking tube, $5 \mathrm{ml}$ volume) such that each bag contained the equivalent of $0.2 \mathrm{~g}$ dry fibre. Each bag was placed in a $250 \mathrm{ml}$ conical flask which contained $100 \mathrm{ml}$ PEG solution of known suction pressure (range $0-10^{7} \mathrm{~N} / \mathrm{m}^{2}$; Robertson \& Eastwood, $1981 \mathrm{~b}$ ). The flask was sealed and vigorously shaken at room temperature for $72 \mathrm{~h}$ on an Orbital Shaker $(100 \mathrm{rev} / \mathrm{min})$. Sodium azide $(\mathrm{g} / \mathrm{g})$ was used as a bacteriostat and was shown to have no effect on WHC (Robertson \& Eastwood, $1981 \mathrm{~b}$ ). The fresh weight content of each bag was determined before drying to determine WHC. The results calculated have been expressed as $\mathrm{g}$ fibre/ $\mathrm{g}$ water. The coefficient of variation between replicate samples for WHC determined using PEG was $8 \cdot 2$ (range $2 \cdot 5-18$ ).

Water flow measurement. Flow-rate measurements were made at room temperature using a chromatography column $300 \times 8 \mathrm{~mm}$ (Pharmacia, Upsalla, Sweden). The column was packed with pre-soaked fibre. The fibre was allowed to settle under the weight of a $60 \mathrm{~g}$ packing rod. A pressure difference of $1 \mathrm{~m}\left(10^{4} \mathrm{~N} / \mathrm{m}^{2}\right)$ was used to run water through the column by ascending flow. Compaction of the fibre did not occur at the pressure difference used to measure flow-rate. Flow was measured by collecting the column effluent over a period of time $(1 \mathrm{~h})$. Flow has been assumed to occur through porous particles rather than round particles of fibre. The dry weight of fibre packing in the column was measured at the completion of each experiment. The density of the packing was measured from the weight of fibre and measured volume of column $(18 \mathrm{ml})$. The flow-rate was measured as $\mathrm{ml}$ buffer collected $/ \mathrm{h}$. Three collections were made for each column. 


\section{Human studies}

Subjects. For the potato-fibre studies, seven male volunteers aged between 26 and 44 years were used. For the study which used wheat bran, nine male subjects were used aged between 25 and 43 years. All were members of the laboratory and clinical staff of the unit. Two subjects only participated in one study.

Diet studies. Subjects were studied whilst continuing their normal routine. The experimental design was similar for each trial and consisted of a 1 week control period followed by a 3-week period with fibre supplement. Each subject acted as his own control. Diet histories were taken both by $24 \mathrm{~h}$ recall interview and by a diet diary kept during each period of stool collection. Stool collections were confined to the control week and the final week of fibre supplementation.

Air-dried and roller-dried potato preparations were taken in $150 \mathrm{ml}$ milk to enhance the fibre palatability. Boiled potato fibre was taken with tomato soup $(500 \mathrm{ml})$ for the same reason. During each control week the milk or soup was taken without the fibre. Bran was eaten raw with milk and sugar. For experiments with potato concentrate, $20 \mathrm{~g} / \mathrm{d}$ were taken and with bran, $16 \mathrm{~g} / \mathrm{d}$ were taken.

Measurements made. All measurements made during the control week were repeated during the third week of each trial. A control week consisted of taking forty radio-opaque markers at a specified time ( 08.00 hours) on the first day to measure intestinal transit time (Hinton et al. 1969) and individually collecting all stools excreted over the next $7 \mathrm{~d}$. Stools were frozen at $-20^{\circ}$ until required for processing. The time taken for $80 \%$ of the markers to appear in the faeces was taken as the transit time. In each experiment more than $95 \%$ of the markers were identified, which indicated complete collection of the faeces passed during the experiment.

After measurement of transit time and wet weight the stools were thawed, homogenized and a portion of each pooled collection freeze-dried. The resultant powder was used to determine the dry weight and for subsequent chemical analyses for faecal fat (Varley, 1966) and faecal bile acids (Evrard \& Janssen, 1968). On the third morning (09.00 hours) of each faecal trial week (control and after 3 weeks of the fibre supplement), blood for serum cholesterol analysis (Roschlau et al. 1974) was removed by venepuncture after fasting from 19.00 hours the previous evening. After blood was taken the normal daily routine was followed.

The time-interval between experiments was at least 3 months. All trials were conducted after approval by the North Lothian District Ethics of Research Committee.

\section{RESULTS}

\section{Water-holding studies}

The chemical composition, WHC and flow-rates for each fibre preparation are shown in Table 1. All preparations contained starch. The method of fibre drying did not affect the chemical composition but chemical composition was different for the cereal-and potato-fibre preparations. Cereal bran has a high hemicellulose but low cellulose content whilst potato has a high proportion of pectin, lignin and cellulose. WHC, as measured by centrifugation and filtration, also differed between bran and potato fibre, bran having a lower WHC. Potato fibre which had been dried and rehydrated had a reduced WHC compared with boiled potato fibre. Measurement of WHC by filtration and centrifugation did not eliminate these differences but at a given suction pressure all potato-fibre preparations had a similar WHC. Flow-rate measurement under the conditions used showed cereal fibre to allow a much higher flow-rate than potato fibre. Flow-rate through potato fibre was similar for each preparation and was not related to packing density. 


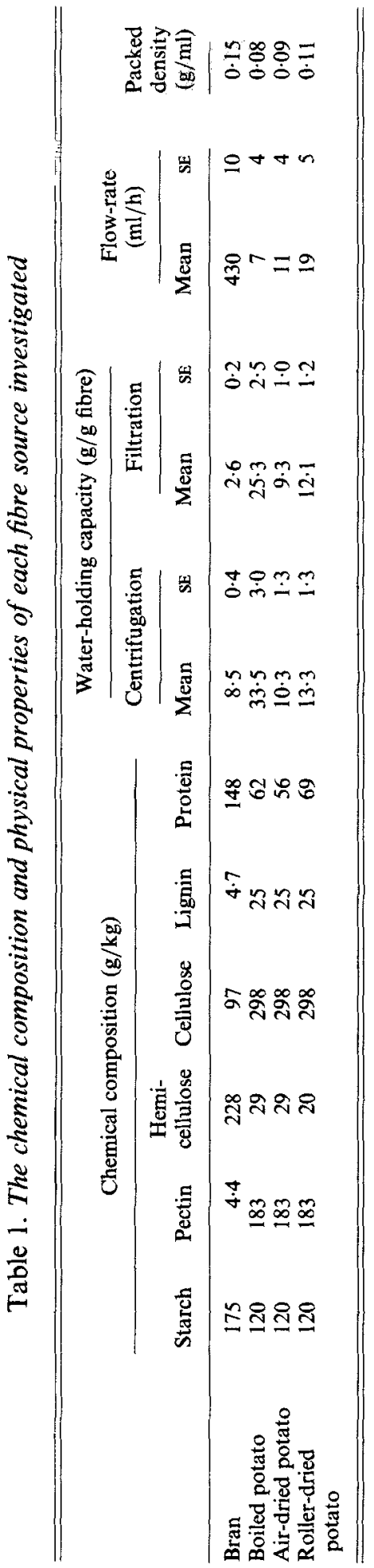




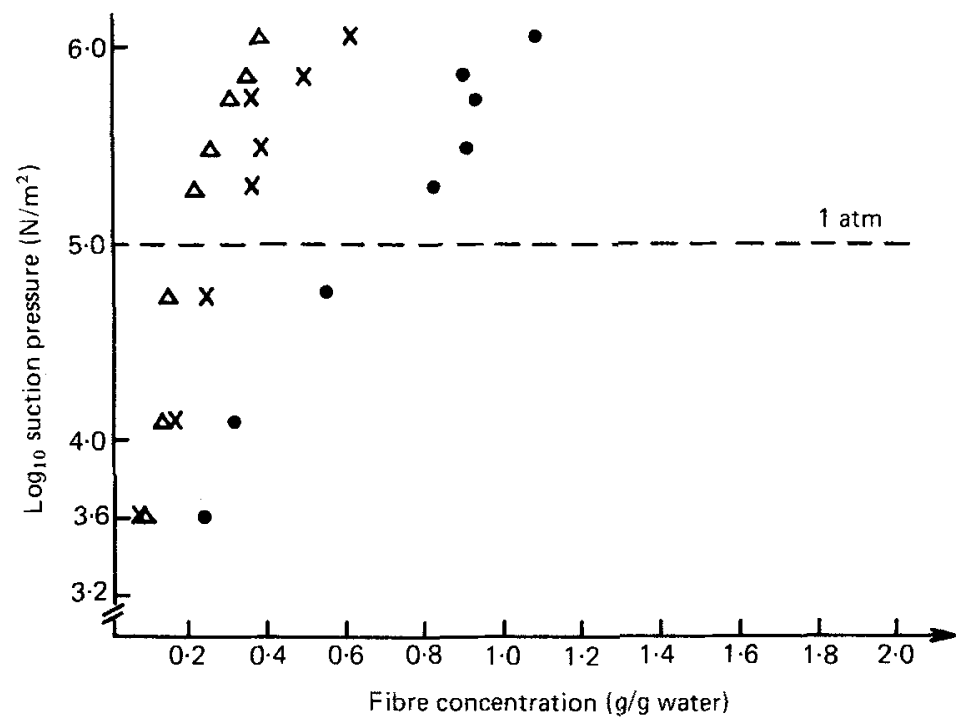

Fig. 1. The effect of suction pressure on the water-holding capacity (WHC) of fibre. (O), Bran; $(x)$, potato fibre; $(\triangle)$, gum arabic. To convert fibre concentration $(\mathrm{g} / \mathrm{g}$ water) to WHC, $0 \cdot 2=5 \mathrm{~g}$ water $/ \mathrm{g}$ fibre; $2 \cdot 0=0.5 \mathrm{~g}$ water $/ \mathrm{g}$ fibre.

Table 2. Particle size distribution of fibre sources investigated

\begin{tabular}{|c|c|c|c|c|c|c|c|}
\hline \multirow[b]{2}{*}{ Sieving tests $(\mathrm{mm})}$. & \multicolumn{6}{|c|}{ Percentage passing through the seive } & \multirow[b]{2}{*}{$3 \cdot 55+$} \\
\hline & $0 \cdot 25$ & $0 \cdot 40$ & 0.63 & 0.74 & 1.50 & $2 \cdot 8$ & \\
\hline \multicolumn{8}{|l|}{ Potato fibre: } \\
\hline Roller dried & 25 & 28 & 37 & 10 & - & - & - \\
\hline Air dried & 33 & 28 & 26 & 13 & - & - & - \\
\hline Bran & - & - & 17 & 31 & 46 & $4 \cdot 1$ & - \\
\hline
\end{tabular}

Fig. 1 shows the effect of suction pressure on the amount of water held by cereal fibre and potato fibre compared with the water-soluble polysaccharide, gum arabic. Bran loses water more readily than either potato fibre or gum arabic. Potato fibre behaves somewhat like a gel in its ability to retain water against a suction pressure. A separate osmotic gradient experiment to compare different potato-fibre preparations showed each preparation used to have a similar water-holding ability. Table 2 shows the particle size distribution of the fibre preparations used.

\section{Human experiments}

The dietary intakes during the experiments are shown in Table 3. These remained consistent throughout each experiment. Energy intake was approximately $10 \mathrm{MJ} / \mathrm{d}$, of which $12 \%$ was protein, $40 \%$ fat and $48 \%$ carbohydrate. Mean fibre intake during control periods was less than $20 \mathrm{~g} / \mathrm{d}$.

Intestinal transit time, faecal characteristics and serum cholesterol concentration are shown in Table 4. None of the potato-fibre preparations investigated had any statistically significant effect on colonic function or serum cholesterol. In the experiment with bran, 


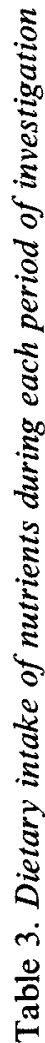
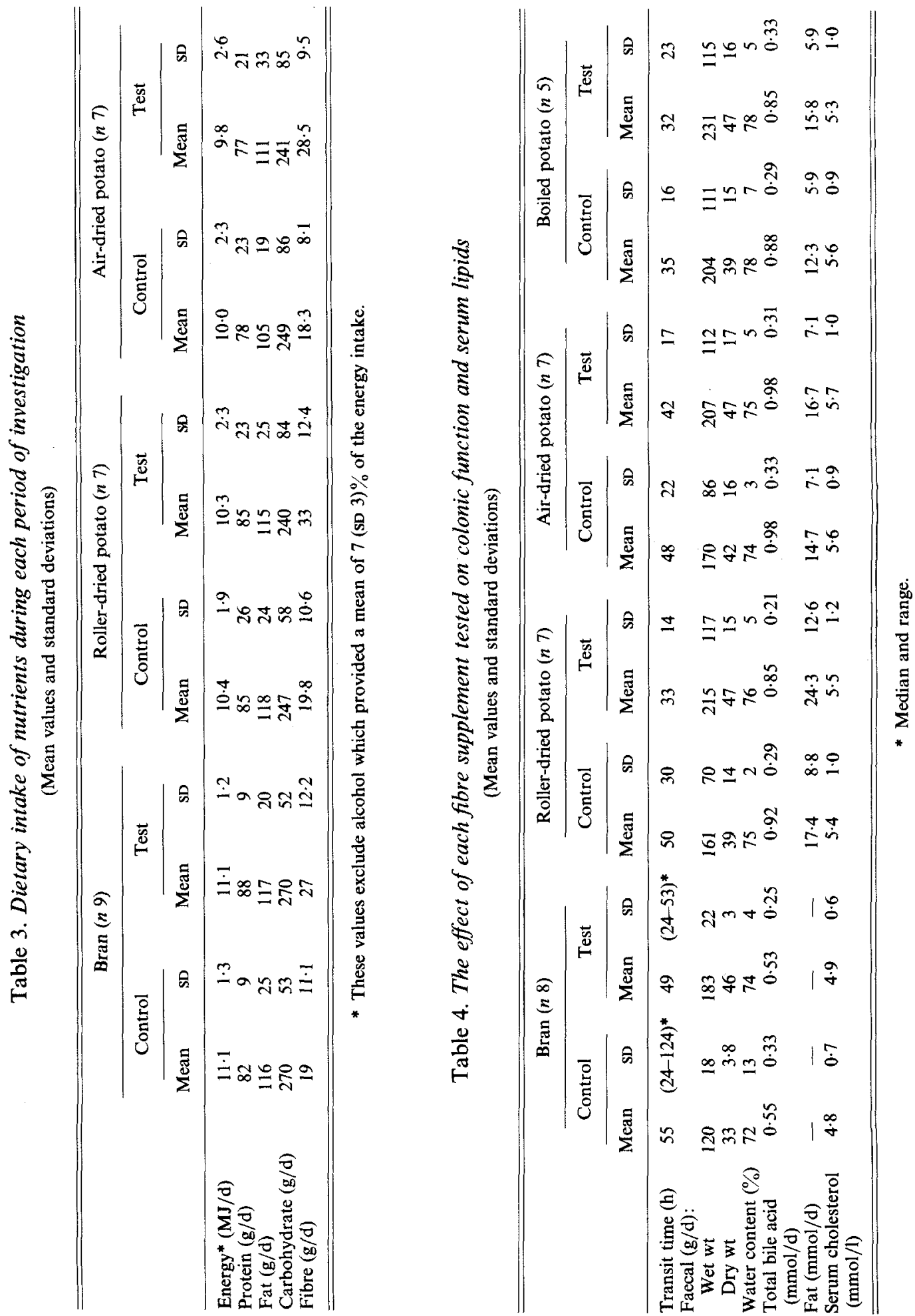
however, faecal wet weight and dry weight increased significantly $(P<0.001)$, although transit time decrease was not significant and faecal bile acid and fat excretion were not altered. Bran had no effect on serum cholesterol.

\section{DISCUSSION}

Fibre has been reported to have diverse effects on function along the gastrointestinal tract, influencing gastric emptying time, intestinal absorption, caecal fermentation and faecal weight (Spiller \& Kay, 1980). It appears to influence each of these functions in a manner peculiar to the fibre source and it may not follow that fresh or concentrated preparations from the same fibre source would behave in an equivalent manner. For example, if wheat bran is cooked the effect predicted from raw bran is not found (Wyman et al. 1976). This may result from changes in the chemistry or physical properties of the fibre.

There is a requirement for simple reproducible methods which would enable a fibre to be classified into broad categories of action along the gastrointestinal tract.

It is known that cereal bran can predictably increase stool weight and that the WHC of the bran is a reasonable predictor of the efficacy (Smith et al. 1981). The viscosity of a gum is an indicator of its effect on gastric emptying and constraining effect on glucose absorption (Jenkins et al. 1978). However, such physical methods are not helpful for fruit and vegetables where and inverse relationship has been shown between the WHC of a fibre and their effect on stool weight (Stephen \& Cummings, 1979). It has been suggested that the pentosan content of fibre can predict stool weight increase (Cummings et al. 1978) but gum arabic, which is rich in pentoses, has little effect on stool weight (Ross et al. 1983).

In a series of studies (Robertson \& Eastwood, $1981 a, b, c$ ), experimental conditions which could affect the WHC of dietary fibre have been examined. The conclusion of the latter studies was that the manner in which water is held by the fibre matrix may be more relevant to understanding the role of fibre in nutrition than the actual amount held.

However, all chemical and physical properties may be altered by fermentation. Therefore a combined property, i.e. chemical structure, physical property and fermentability of a fibre source may be all important.

Water can be held as either trapped or bound water. Methods that have been used to study WHC and the different phases in which water is held include centrifugation, filtration, column chromatography and measuring WHC against an osmotic pressure.

Using centrifugation the WHC can vary within a fibre source, such as the potato fibre used in the present experiment, depending on the method of fibre preparation. The more severe the method of drying the lower the WHC of the potato fibre. The WHC can also be influenced by the method of measurement (Robertson \& Eastwood, 1981 b). Such differences due to preparation and measurement make it difficult to resolve different questions in the role of fibre in the diet. The high WHC of vegetable fibre may be due to vegetable fibre having a greater ability than cereal fibre to trap water within the cell matrix. It is possible, however, that a measure of bound water rather than the total water may be useful in predicting caecal fermentation and effect on stool weight.

Water can be considered to be held by fibre in three phases. Phase 1 is water bound by the hydrophilic polysaccharide of the fibre. The water is unavailable and the amount bound depends on the chemical composition of the fibre. Phase 2 is water held by the fibre in the fibre matrix. This water is available water but availability depends on the pore size distribution of the fibre matrix. Pore size determines the amount of matrix water present in fibre. Phase 3 is water trapped within the cell wall lumen and is readily available.

The amount of trapped water present in fibre will depend on the fibre source, mode of preparation and method of measurement. Centrifugation and filtration measures the total of phases 1, 2 and 3 although, curiously, the centrifugation method gives a larger value than 
the filtration method. This may be due to an elastic recoil of the pressurized fibre after centrifugation (Robertson \& Eastwood, 1981a).

The column method and the method using a known suction pressure measures how strongly water is held by the fibre matrix. These two methods attempt to quantify the two phases. A distinction between phase 1 and phases 2 and 3 water will be observed in column chromatography. The water flow-rate gives an indication of how the water is held, i.e. removed easily (fast flow with free water) or strongly bound (slow flow). Measuring WHC against a known osmotic pressure enables another measure of strength of absorption of the water (Robertson \& Eastwood, 1981c).

The experiments in the present paper examined water held by fibre measured by four methods and related this to faecal bulking. In the in vitro experiments coarse wheat bran was compared with three preparations of potato fibre.

The complexities of these studies are shown by the different results obtained in this study for potato-fibre concentrate (Schweitzer \& Würsch, 1981) compared with those for raw potato (Southgate, 1978). This illustrates the variation introduced both by the mode of preparation and the method of analysis. It is noteworthy that the separation of fibre from the raw mass of potato is selective and determined by the chance influences of the extraction conditions.

The three preparations of potato fibre had very different WHC as measured by centrifugation and filtration. The water flow-rate and response to a range of osmotic suction pressures, however, was indistinguishable between the three preparations. This suggests that the phase 1 water is constant and the variability is to be found in phases 2 and 3 which are less dependent upon the chemistry of the fibre than of the physical properties of the preparation.

These fibre preparations are compared with a coarse wheat bran which is chemically quite distinct. The particle size distribution of the potato and bran fibres is very different (Table 2). Wheat bran predictably increases faecal weight to an extent dictated by the WHC measured by centrifugation.

The bran had the expected effects on the factors measured but the potato fibre concentrates had no statistically-significant influence on stool weight despite the range of WHC (10-33 g water $/ \mathrm{g}$ fibre). However, the mean stool weight did increase by $54 \mathrm{~g}$ for roller dried, $37 \mathrm{~g}$ for air-dried and $27 \mathrm{~g}$ for boiled potato-fibre concentrate, though this did not achieve statistical significance either by parametric or non-parametric analysis. The smallest increase was found with boiled potato, the preparation with the highest WHC ( $33 \mathrm{~g} / \mathrm{g}$ fibre). This is consistent with previous findings relating WHC to stool weight (Stephen \& Cummings, 1979).

As has been shown for other fibre concentrates our experiments show that wheat bran and potato fibre have no effect on serum cholesterol concentrations. It has previously been shown that eating $1 \mathrm{~kg}$ potatoes $/ \mathrm{d}$ ( $21 \mathrm{~g}$ dietary fibre) caused stool weight to increase from 149 (SE 45) g during the control period of 249 (SE 86) g during the experimental period (Flynn et al. 1977). This intake had no effect on serum cholesterol. The fibre intake was similar to that of our experiments using potato-fibre concentrates though the potatoes were eaten for a longer period (at least 10 weeks). This comparison of potato and potato concentrate suggests that fibre concentrates may behave differently from 'natural fibre' along the gastrointestinal tract (Cummings et al. 1978; Robertson et al. 1979).

Since WHC did not appear to be related to dietary effect for the potato-fibre preparations it was thought that the 'strength' with which the water was held might be a better predictor of dietary effect (i.e. water-holding ability).

It has been shown that the potato fibre holds water strongly in a similar manner to gum arabic. In separate experiments gum arabic has been shown to have little or no effect on stool weight in man and is probably totally fermented in the caecum as suggested by an 
increased breath hydrogen excretion (Ross et al. 1983). This suggests that the potato fibre is fermented in the caecum, though no measurements confirming this, e.g. breath hydrogen, were made. It is interesting that gum arabic ingestion was not associated with any change in faecal bile acid excretion but there was a modest decrease in the serum cholesterol. Such changes in sterol metabolism were not found for the potato fibre of any WHC.

These experiments suggest that WHC, as measured by centrifugation or filtration, have no value in predicting the biological efficacy of a fibre of fruit or vegetable origin. It is possible that a fibre which strongly binds water in phase 1 will not influence stool weight. On the other hand, a fibre which has a loose association with water is a ready enhancer of stool weight. The mechanism of the variability of fruit and vegetable fibre must be related to the somewhat indirect influence through proliferation of bacteria.

These possibilities can only be substantiated through more experiments. However, human experiments are time-consuming, especially when the same subjects go through repeated trials. There has to be a period between each experiment of unknown duration, at least 1 month (Eastwood et al. 1973), otherwise there is carry-over effect into the next experiment. Therefore these experiments need to be conducted in an animal model. In such a study the relationship of water and fibre along the gastrointestinal tract can be properly assessed.

The authors would like to thank Nordreco/Nestlé, Bjuv, Sweden and the Incorporated National Association of British and Irish Millers Ltd, London, for financial assistance.

\section{REFERENCES}

Cummings, J. H., Southgate, D. A. T., Branch, W., Houston, H., Jenkins, D. J. A. \& James, W. P. T. (1978). Lancet i, 5-9.

Eastwood, M. A., Brydon, W. G. \& Tadesse, K. (1980). In Medical Aspects of Dietary Fiber, pp. 1-26 [G. A. Spiller and R. M. Kay, editors]. New York: Plenum Medical Book Co.

Eastwood, M. A., Kirkpatrick, J. R., Mitchell, W. D., Bone, A. \& Hamilton, T. (1973). British Medical Journal 4, 392-394.

Evrard, E. \& Janssen, G. (1968). Journal of Lipid Research 9, 226-236.

Flynn, J. F., O'Beirn, S. F. O. \& Burkitt, D. P. (1977). Irish Journal of Medical Science 146, 285-288.

Hellendoorn, E. W. (1978). In Topics in Dietary Fibre Research. pp. 127-168 [G. A. Spiller, editor]. New York: Plenum Medical Book Co.

Hinton, J. H., Lennard-Jones, J. E. \& Young, A. C. (1969). Gut 10, 842-847.

Jenkins, D. J. A., Wolever, T. M. S., Leeds, A. R., Gassull, M. A., Haisman, P., Diliwari, J., Goff, D. V., Metz, G. L. \& Alberti, K. G. M. M. (1978). British Medical Journal i, 1392-1394.

Kelsay, J. L. (1978). American Journal of Clinical Nutrition 31, 142-159.

McConnell, A. A., Eastwood, M. A. \& Mitchell, W. D. (1974). Journal of the Science of Food and Agriculture 25, 1457-1464.

Robertson, J. A., Brydon, W. G., Tadesse, K., Wenham, P., Walls, A. \& Eastwood, M. A. (1979). American Journal of Clinical Nutrition 32, 1889-1892.

Robertson, J. A. \& Eastwood, M. A. (1981 a). Journal of the Science of Food and Agriculture 32, 819-825.

Robertson, J. A. \& Eastwood, M. A. (1981 b). British Journal of Nutrition 45, 83-87.

Robertson, J. A. \& Eastwood, M. A. (1981 c). British Journal of Nutrition 46, 247-255.

Roschlau, P., Bernt, E. \& Gruber, W. (1974). Zeitschrift für Klinische Chemie und Klinische Biochemie 12, $403-407$.

Ross, H. McL., Eastwood, M. A., Brydon, W. G., Anderson, J. R. \& Anderson D. M. W. (1983). American Journal of Clinical Nutrition 37 368-375.

Schweitzer, T. F. \& Würsch, P. (1981). In Analysis of Dietary Fiber in Foods, pp. 203-216 [W. P. T. James and O. Theander, editors]. New York: Marcel Dekker Inc.

Smith, A. N., Drummond, E. \& Eastwood, M. A. (1981). American Journal of Clinical Nutrition 34, $2460-2463$. Southgate, D. A. T. (1978). American Journal of Clinical Nutrition 31, S107-S110.

Spiller, G. A. \& Kay, R. M. (1980). Medical Aspects of Dietary Fiber. New York: Plenum Medical Book Co.

Stephen, A. M. \& Cummings, J. H. (1979). Gut 20, 722-729.

Stephen, A. M. \& Cummings, J. H. (1980a). Journal of Medical Microbiology 13, 45-56.

Stephen, A. M. \& Cummings, J. H. (1980b). Nature 284, 283-284.

Van Soest, P. J. \& McQueen, R. W. (1973). Proceedings of the Nutrition Society 32, 123-130.

Varley, H. (1966). Practical Clinical Biochemistry, 3rd ed, p. 349. London: Heinemann Medical Book Co.

Wyman, J. B., Heaton, K. W., Manning, A. P. \& Wicks, A. C. B. (1976). American Journal of Clinical Nutrition 29, $1474-1479$. 